\title{
Freeze-all cycle in reproductive medicine: current perspectives
}

\author{
Matheus Roque ${ }^{1,2}$, Marcello Valle ${ }^{1}$, Alessandra Kostolias ${ }^{1}$, Marcos Sampaio ${ }^{3}$, Selmo Geber ${ }^{2,3}$ \\ ${ }^{1}$ ORIGEN - Center for Reproductive Medicine, Rio de Janeiro, Brazil \\ 2 UFMG, Federal University of Minas Gerais, Belo Horizonte, Brazil \\ ${ }^{3}$ ORIGEN - Center for Reproductive Medicine, Belo Horizonte, Brazil
}

\begin{abstract}
The freeze-all strategy has emerged as an alternative to fresh embryo transfer (ET) during in vitro fertilization (IVF) cycles. Although fresh ET is the norm during assisted reproductive therapies (ART), there are many concerns about the possible adverse effects of controlled ovarian stimulation (COS) over the endometrium. The supra-physiologic hormonal levels that occur during a conventional COS are associated with modifications in the peri-implantation endometrium, which may be related to a decrease in pregnancy rates and poorer obstetric and perinatal outcomes when comparing fresh to frozenthawed embryo transfers. The main objective of this study was to assess the available literature regarding the freezeall strategy in IVF cycles, in regards to effectiveness and safety. Although there are many potential advantages in performing a freeze-all cycle over a fresh ET, it seems that the freeze-all strategy is not designed for all IVF patients. There is a need to develop a non-invasive clinical tool to evaluate the endometrial receptivity during a fresh cycle, which enables the selection of patients that would benefit from this strategy. Today, it is reasonable to perform elective cryopreservation of all oocytes/embryos in cases with a risk of OHSS development, and in patients with supra-physiologic hormonal levels during the follicular phase of COS. It is not clear if all normal responders and poor responders may benefit from this strategy.
\end{abstract}

Keywords: freeze-all, elective frozen-thawed embryo transfer, delayed frozen-thawed embryo transfer, cryopreservation, IVF

\section{INTRODUCTION}

Although fresh ET is the norm during assisted reproductive therapies (ART), in the past few years, the freeze-all strategy has emerged as an alternative to fresh embryo transfer (ET) during in vitro fertilization (IVF) cycles (Roque, 2015a). Controlled ovarian stimulation (COS) is necessary for the development and maturation of many follicles and oocytes, thus increasing the likelihood of positive outcomes and cumulative pregnancy rates during ART (Siristatidis et al., 2013). However, there are many concerns about the possible adverse effects of controlled ovarian stimulation (COS) over the endometrium. The supra-physiological hormonal levels that occur during a conventional COS are associated with modifications in the peri-implantation endometrium, that may be related to decreases in pregnancy rates (Shapiro et al., 2011a; Roque et al., 2013), and poorer obstetric and perinatal outcomes (Maheshwari et al., 2012; Pandey et al., 2012; Pinborg et al., 2013), when comparing fresh to frozenthawed embryo transfers.

In the freeze-all strategy, the entire cohort of embryos is cryopreserved (not just the "second best"), and the best embryos are transferred in a later cycle into a more physiologic endometrium (Roque, 2015a). IVF success depends not only on embryo quality, but also on endometrial receptivity and on the embryo-endometrium interaction, these modifications in uterine environment, found during COS, may jeopardize the IVF outcomes after fresh embryo transfer, when compared to FET. By performing delayed frozen-thawed ET (FET), the deleterious effects of COS over the endometrium would be avoided, and better outcomes could be expected (Shapiro et al., 2011a; Roque et al., 2013; Roque, 2015a).

The main objective of this study was to assess the available literature regarding the effectiveness and safety of the freeze-all strategy in IVF cycles.

\section{The rationale of freeze-all cycles}

There is scientific evidence showing that COS may be related to endometrial advancement, which can be seen during histological evaluation in a fresh IVF cycle (Ubaldi et al., 1997; Kolibianakis et al., 2002). In 1997 Ubaldi et al. performed endometrial biopsies during a fresh cycle and evaluated the histological dating. They reported that when the endometrial advancement was over 3 days, no pregnancy was achieved. All these patients had progesterone $(p)$ levels $\geq 1.1 \mathrm{ng} / \mathrm{mL}$ on the trigger day. The mean number of retrieved oocytes in this group of patients was 15.8 . In the group of patients with lower $p$ levels, the endometrial advancement was of 3 days or less, suggesting no interference of ovarian stimulation over the endometrium in this group of patients (Ubaldi et al., 1997). These findings were later corroborated by the study carried out by Kolibianakis et al. (2002).

The technique used to evaluate the endometrium has evolved, and in 2005 Horcajadas et al. published a study evaluating the endometrium gene expression profile. They performed endometrial biopsies in the same oocyte donors during a fresh cycle on the $7^{\text {th }}$ day after $\mathrm{LH}$ surge, and compared it to endometrial samples on the $7^{\text {th }}$ day after hCG trigger in a stimulated cycle. They found that there were over 200 genes related to implantation that were over or under expressed during COS, when compared to a natural cycle. These changes may be associated with the supra-physiologic hormonal levels observed during COS. Labarta et al. (2011) found differences in endometrial gene expression between patients with elevated $p$ $(\geq 1.1 \mathrm{ng} / \mathrm{mL})$ on the day of final oocyte maturation, when compared with patients with normal $p$ levels. Van Vaerenbergh et al. (2009) showed a correlation between endometrial dating by Noyes' criteria and endometrial gene expression. They also found that patients that had endometrial advancement of more than 3 days did not get pregnant, and they correlated these histological findings with the gene expression profile.

The aforementioned studies suggested that hyperstimulation might be detrimental to implantation, by altering genes that are crucial for the endometrium-embryo 
interaction. However, all altered findings (histological and gene expression profile) were found in patients with normal to high ovarian response (Ubaldi et al., 1997; Kolibianakis et al., 2002; Horcajadas et al., 2005; Labarta et al., 2011). For example, in the protocol implemented by Horcajadas et al. (2005), COS resulted in the retrieval of 13-18 oocytes and an average $E_{2}$ level of $2200 \mathrm{pg} . / \mathrm{mL}$. Thus, until now, we cannot extrapolate these findings to patients with all subtypes of ovarian response.

These modifications in the endometrium, occurring because of COS, may have consequences not only on implantation rates during IVF treatments, but also be associated with obstetric and perinatal complications. Epidemiologic studies suggest that the maternal periimplantation environment plays a critical role in perinatal outcomes (Mainigi et al., 2014). It was shown in animal models that the altered hormonal milieu related to gonadotropin administration plays a critical role and has a direct effect over fetal growth, trophoblast differentiation, and gene expression. The exact cellular and molecular mechanisms are not well established. However, it seems that altered trophoblast expansion and invasion is, at least in part, responsible for the consequences (Mainigi et al., 2014).

\section{Effectiveness}

A recent meta-analysis (Roque et al., 2013) showed an increase of $32 \%$ in the ongoing pregnancy rate when the freeze-all strategy was performed, when compared to fresh $\mathrm{ET}^{4}$. However, there were only three studies included in this meta-analysis (Aflatoonian et al., 2010; Shapiro et al., 2011a, Shapiro et al., 2011b), and one of them (Aflatoonian et al., 2010) was recalled due to methodological problems. We performed another analysis excluding the aforementioned study, as shown in Figure 1. The analysis of the available data also showed that eFET resulted in a statistically significant increase in the clinical pregnancy rate when compared to the rate found with fresh embryo transfer $(\mathrm{RR}=1.28,95 \%$ confidence interval [CI]: 1.03-1.60; $\mathrm{I}^{2}=0 \%$ ) (Figure 1A). Nonetheless, when we evaluated ongoing pregnancy rates (OPR), the eFET group showed a higher OPR compared to the fresh embryo transfer group, but this difference did not reach statistical significance $\left(\mathrm{RR}=1.26,95 \% \mathrm{CI}: 1.00-1.58 ; \mathrm{I}^{2}\right.$ $=0 \%$ ) (Figure 1B). This new analysis included 259 in vitro fertilization (IVF) cycles in normal and high responders following blastocyst embryo transfers, considering two studies from the same reproductive center (Fig 1). This data has been already published in the comments of the previous published study (Roque et al., 2013) on the Fertility and Sterility website.

Ferrareti et al. (1999) published a study comparing elective cryopreservation of all embryos to fresh embryo transfer in patients with risk of OHSS development. They did not find any benefit in delaying ET. However, this was a study from 17 years ago, and these findings may be associated with the cryopreservation techniques used in 1999 and not with the strategy per se. A randomized clinical trial (RCT) (Chen et al., 2016) was recently published, evaluating 1508 infertile women with polycystic ovary syndrome, who were submitted to a first IVF cycle, comparing fresh embryo transfer to elective FET. The patients in the freeze-all group had a higher frequency of live births after the first transfer, when compared to fresh embryo transfers ( $49.3 \%$ vs. $42.0 \%, p=0.004)$. These results were mainly due to a lower frequency of pregnancy loss in the freeze-all group ( $R R=0.67 ; 95 \%$ CI $0.54-0.83$; $p<0.001)$. Thus, until now, there are only three recent RCT concerning the freeze-all strategy.

All previous studies evaluating this strategy were performed in patients with normal/high ovarian response (Shapiro et al., 2011a; Shapiro et al., 2011b; Roque et al., 2015c; Braga et al., 2016; Chen et al., 2016). Therefore, it is not possible to extrapolate the results to all kinds of ovarian response, such as poor ovarian responders (POR). Until now, there are no studies evaluating this strategy in POR. Moreover, these studies showed that although this strategy would lead to improvements in IVF outcomes of at least 30\% in CPR and OPR when compared to fresh embryo transfers (Shapiro et al., 2011a; Shapiro et al., 2011b;

A

\begin{tabular}{|c|c|c|c|c|c|c|c|c|c|}
\hline \multirow[b]{2}{*}{ Study or Subgroup } & \multicolumn{2}{|c|}{ Frozen-Thawed } & \multicolumn{2}{|c|}{ Fresh } & \multirow[b]{2}{*}{ Weight } & \multirow{3}{*}{$\begin{array}{c}\text { Risk Ratio } \\
\text { M-H, Fixed, 95\% CI }\end{array}$} & \multirow{2}{*}{\multicolumn{3}{|c|}{$\begin{array}{c}\text { Risk Ratio } \\
\text { M-H, Fixed, 95\% Cl }\end{array}$}} \\
\hline & Events & Total & Events & Total & & & & & \\
\hline Aftatoonian 2010 & 78 & 187 & 58 & 187 & $0.0 \%$ & & & & \\
\hline Shapiro 2011 - Normal & 42 & 70 & 29 & 67 & $47.0 \%$ & $1.39[0.99,1.94]$ & & & \\
\hline Shapiro 2011 - High & 39 & 60 & 34 & 62 & $53.0 \%$ & $1.19[0.88,1.59]$ & & & \\
\hline Total $(95 \% \mathrm{Cl})$ & & 130 & & 129 & $100.0 \%$ & $1.28[1.03,1.60]$ & & & \\
\hline Total events & 81 & & 63 & & & & & & \\
\hline $\begin{array}{l}\text { Heterogeneity: } \text { Chi }^{2}=0.4 \\
\text { Test for overall effect: } Z\end{array}$ & $\begin{array}{l}d f=1(P=0 \\
2.18(P=\end{array}$ & $; 1^{2}=0 \%$ & & & & & 0.5 & $\begin{array}{ll}0.7 & 1 \\
\text { Favours Fresh } & 1\end{array}$ & Fave \\
\hline
\end{tabular}

B

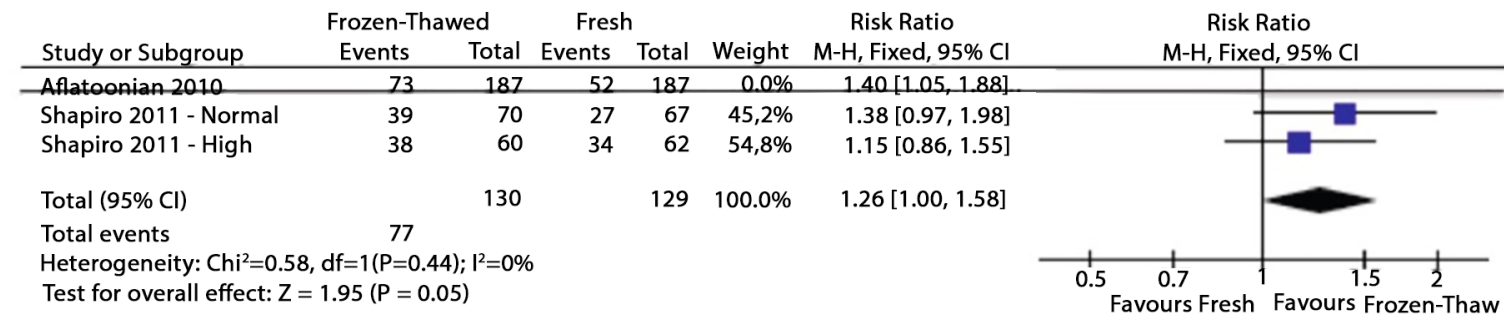

Figure 1- Forest plot of elective frozen-thawed embryo transfers versus fresh embryo transfers: A - Clinica pregnancy rate; and B - Ongoing pregnancy rate. 
Roque et al., 2015c; Braga et al., 2016; Chen et al., 2016), there are also many patients that get pregnant even after fresh embryo transfers. To date, there is no effective noninvasive clinical tool to evaluate ER. This tool would help select those patients without alterations in ER that should be maintained in the fresh embryo transfer, and select patients that really benefit from the freeze-all strategy.

More randomized clinical trials (RCT) evaluating this strategy are necessary, and not only in normal and high responders. There are some registered RCT aiming to evaluate this strategy (NCT00823121, NCT02148393, NCT02471573, NTR3187, ACTRN 12612000422820, HTA $13 / 115 / 82$ ), and we will probably have more robust evidence when these studies are concluded.

\section{Safety}

When elective FET was implemented, the main idea was to improve IVF outcomes. However, it is important to evaluate not only the effectiveness of ART, but also its safety. One of the major complications observed during COS in IVF cycles is ovarian hyperstimulation syndrome (OHSS). It is iatrogenic, potentially lethal and occurs in approximately $1 \%-14 \%$ of ART cycles (Nastri et al., 2010). Nowadays, it is fundamental to prevent the development of OHSS. When the final oocyte maturation with GnRH agonist is performed in patients with an antagonist protocol and all oocytes/embryos are cryopreserved, the onset of early and late OHSS is virtually eliminated (Devroey et al., 2011; Kol \& Humaidan, 2013).

The uterine environment during fresh embryo transfers differs from that during FET. In a stimulated cycle, there may be an increase in uterine contractility and embryoendometrium asynchrony. This would lead to an increase in the risk of ectopic pregnancy (EP) when comparing fresh transfer to FET (Huang et al., 2014; Londra et al., 2015). Moreover, there is lower risk of low birth weight (Pinborg et al., 2010; Li et al., 2014; Ishihara et al., 2014), preterm birth (Pelkonen et al., 2010; Pinborg et al., 2013; Wennerholm et al., 2013; Ishihara et al., 2014; Schwarze et al., 2015), small for gestational age (Ishihara et al., 2014; Li et al., 2014; Pinborg et al., 2014) after FET when comparing to fresh ET. However, the FET cycles are associated with a higher incidence of large for gestational age (Wennerholm et al., 2013; Pinborg et al., 2014), and higher risk of placenta accreta (Ishihara et al., 2014; Kaser et al., 2015). It is still controversial if the risk of hypertensive disorders is increased or not among FET patients when compared to their fresh cycles counterparts.

\section{Cost-effectiveness}

There is a lack of studies evaluating the cost-effectiveness of the freeze-all policy. To our knowledge, there is only one published study evaluating this (Roque et al., 2015b). The authors concluded that this strategy was cost-effective when compared to fresh embryo transfers. More studies are necessary to evaluate the incremented costs when performing elective cryopreservation of all embryos.

\section{CONCLUSION}

Although there are many potential advantages in performing a freeze-all cycle over a fresh ET, it seems that the freeze-all strategy is not suited for all IVF patients. There are many patients that get pregnant and don't have any obstetrical/perinatal complication even after fresh ET. Moreover, there is a need for studies comparing the costs and cumulative pregnancy rates between the two strategies. There is a need to develop a non-invasive clinical tool to evaluate endometrial receptivity during a fresh cycle, which may enable the selection of patients that would benefit from this strategy. To date, it is reasonable to perform elective cryopreservation of all oocytes/ embryos in cases with a risk of OHSS development and in patients with supra-physiologic hormonal levels during the follicular phase of COS. It is not clear if all normal responders and poor responders may benefit from this strategy. All other cases should be discussed with the patients, evaluating the pros and cons, including potential costs, delays in treatment, and potential risks associated with this strategy.

\section{CONFLICT OF INTERESTS}

No conflict of interests has been declared.

\author{
Corresponding author: \\ Matheus Roque \\ ORIGEN - Center for Reproductive Medicine, \\ Reproductive Department, \\ Rio de Janeiro, RJ, Brazil, \\ e-mail: matheusroque@origen.com.br
}

\section{REFERENCES}

Aflatoonian A, Oskouian H, Ahmadi S, Oskouian L. Can fresh embryo transfers be replaced by cryopreservedthawed embryo transfers in assisted reproductive cycles? A randomized controlled trial. J Assist Reprod Genet. 2010;27:357-63. Retraction in: J Assist Reprod Genet. 2013;30:1245. PMID: 20373015 DOI: http://dx.doi.org/10.1007/s10815-010-9412-9

Braga DP, Setti AS, Figueira RC, Azevedo MdeC, Iaconelli A Jr, Lo Turco EG, Borges E Jr. Freezeall, oocyte vitrification, or fresh embryo transfer? Lessons from an egg-sharing donation program. Fertil Steril. 2016;106:615-22. PMID: 27262501 DOI: http://dx.doi.org/10.1016/j.fertnstert.2016.05.004

Chen ZJ, Shi Y, Sun $Y$, Zhang B, Liang $X$, Cao $Y$, Yang J, Liu L, Wei D, Weng N, Tian L, Hao C, Yang D, Zhou F, Shi J, Xu $Y$, Li J, Yan J, Qin $Y$, Zhao $H$, Zhang $H$, Legro RS. Fresh versus Frozen Embryos for Infertility in the Polycystic Ovary Syndrome. N Engl J Med. 2016;375:523-33. PMID: 27509101 DOI: http://dx.doi.org/10.1056/NEJMoa1513873

Devroey P, Polyzos NP, Blockeel C. An OHSS-free Clinic by segmentation of IVF treatment. Hum Reprod. 2011;26:2593-7. PMID: 21828116 DOI: http://dx.doi.org/10.1093/humrep/der251

Ferrareti AP, Gianaroli L, Magli C, Fortini D, Selman HA, Feliciani E. Elective cryopreservation of all pronucleate embryos in women at risk of ovarian hyperstimulation syndrome: efficiency and safety. Hum Reprod. 1999;14:1457-60. PMID: 10357958 DOI: http://dx.doi.org/10.1093/humrep/14.6.1457

Horcajadas JA, Riesewijk A, Polman J, van Os R, Pellicer A, Mosselman S, Simón C. Effect of controlled ovarian hyperstimulation in IVF on endometrial gene expression profiles. Mol Hum Reprod. 2005;11:195-205. PMID: 15695772 DOI: http://dx.doi.org/10.1093/molehr/gah150

Huang B, Hu D, Qian K, Ai J, Li Y, Jin L, Zhu G, Zhang $\mathrm{H}$. Is frozen embryo transfer cycle associated with a significantly lower incidence of ectopic pregnancy? An analysis of more than 30,000 cycles. Fertil Steril. 2014;102:1345-9. PMID: 25241365 DOI: http://dx.doi.org/10.1016/j.fertnstert.2014.07.1245 
Ishihara O, Araki R, Kuwahara A, Itakura A, Saito H, Adamson GD. Impact of frozen-thawed single-blastocyst transfer on maternal and neonatal outcome: an analysis of 277,042 single-embryo transfer cycles from 2008 to 2010 in Japan. Fertil Steril. 2014;101:128-33. PMID: 24268706 DOI: http://dx.doi.org/10.1016/j.fertnstert.2013.09.025

Kaser DJ, Melamed A, Bormann CL, Myers DE, Missmer SA, Walsh BW, Racowsky C, Carusi DA. Cryopreserved embryo transfer is an independent risk factor for placenta accreta. Fertil Steril. 2015;103:1176-84. PMID: 25747133 DOI: http://dx.doi.org/10.1016/j.fertnstert.2015.01.021

KolS, Humaidan P. GnRHagonisttriggering: recentdevelopments. Reprod Biomed Online. 2013;26:226-30. PMID: 23337420 DOI: http://dx.doi.org/10.1016/j.rbmo.2012.11.002

Kolibianakis E, Bourgain C, Albano C, Osmanagaoglu K, Smitz J, Van Steirteghem A, Devroey P. Effect of ovarian stimulation with recombinant follicle-stimulating hormone, gonadotropin releasing hormone antagonists, and human chorionic gonadotropin on endometrial maturation on the day of oocyte pick-up. Fertil Steril. 2002;78:1025-9. PMID: 12413988 DOI: http://dx.doi.org/10.1016/S0015-0282(02)03323-X

Labarta E, Martínez-Conejero fnameJA, Alamá P, Horcajadas JA, Pellicer A, Simón C, Bosch E. Endometrial receptivity is affected in women with high circulating progesterone levels at the end of follicular phase: a functional genomics analysis. Hum Reprod. 2011;26:1813-5. PMID: 21540246 DOI: http://dx.doi.org/10.1093/humrep/der126

Li Z, Wang YA, Ledger W, Edgar DH, Sullivan EA. Clinical outcomes following cryopreservation of blastocysts by vitrification or slow freezing: a population-based cohort study. Hum Reprod. 2014;29:2794-801. PMID: 25316444 DOI: http://dx.doi.org/10.1093/humrep/deu246

Londra L, Moreau C, Strobino D, Garcia J, Zacur H, Zhao $\mathrm{Y}$. Ectopic pregnancy after in vitro fertilization: differences between fresh and frozen-thawed cycles. Fertil Steril. 2015;104:110-8. PMID: 25956363 DOI: http://dx.doi.org/10.1016/j.fertnstert.2015.04.009

Maheshwari A, Pandey S, Shetty A, Hamilton M, Bhattacharya S. Obstetric and perinatal outcomes in singleton pregnancies resulting from the transfer of frozenthawed versus fresh embryos generated through in vitro fertilization treatment: a systematic review and metaanalysis. Fertil Steril. 2012;98:368-77. PMID: 22698643 DOI: http://dx.doi.org/10.1016/j.fertnstert.2012.05.019

Mainigi MA, Olalere D, Burd I, Sapienza C, Bartolomei $M$, Coutifaris C. Peri-implantation hormonal milieu: elucidating mechanisms of abnormal placentation and fetal growth. Biol Reprod. 2014;90:26. PMID: 24352558 DOI: http://dx.doi.org/10.1095/biolreprod.113.110411

Nastri CO, Ferriani RA, Rocha IA, Martins WP. Ovarian hyperstimulation syndrome: pathophysiology and prevention. J Assist Reprod Genet. 2010;27:121-8. PMID: 20140640 DOI: http://dx.doi.org/10.1007/s10815-010-9387-6

Pandey S, Shetty A, Hamilton M, Bhattacharya S, Maheshwari A. Obstetric and perinatal outcomes in singleton pregnancies resulting from IVF/ICSI: a systematic review and meta-analysis. Hum Reprod Update. 2012;18:485- 503. PMID: 22611174 DOI: http://dx.doi.org/10.1093/humupd/dms018
Pelkonen S, Koivunen R, Gissler M, Nuojua-Huttunen S, Suikkari AM, Hydén-Granskog C, Martikainen H, Tiitinen A, Hartikainen AL. Perinatal outcome of children born after frozen and fresh embryo transfer: the Finnish cohort study 1995-2006. Hum Reprod. 2010;25:914-23. PMID: 20124395DOI: http://dx.doi.org/10.1093/humrep/dep477

Pinborg A, Wennerholm UB, Romundstad LB, Loft A, Aittomaki K, Söderström-Anttila V, Nygren KG, Hazekamp J, Bergh C. Why do singletons conceived after assisted reproduction technology have adverse perinatal outcome? Systematic review and meta-analysis. Hum Reprod Update. 2013;19:87-104. PMID: 23154145 DOI: http://dx.doi.org/10.1093/humupd/dms044

Pinborg A, Henningsen AA, Loft A, Malchau SS, Forman J, Andersen AN. Large baby syndrome in singletons born after frozen embryo transfer (FET): is it due to maternal factors or the cryotechnique? Hum Reprod. 2014;29:618- 27. PMID: 24413766 DOI: http://dx.doi.org/10.1093/humrep/det440

Pinborg A, Loft A, Aaris Henningsen AK, Rasmussen $\mathrm{S}$, Andersen AN. Infant outcome of 957 singletons born after frozen embryo replacement: The Danish National Cohort Study 1995-2006. Fertil Steril. 2010;94:1320-7. PMID: 19647236 DOI: http://dx.doi.org/10.1016/j.fertnstert.2009.05.091

Roque M, Lattes K, Serra S, Solà I, Geber S, Carreras R, Checa $M A$. Fresh embryo transfer versus frozen embryo transfer in in vitro fertilization cycles: a systematic review and metaanalysis. Fertil Steril. 2013;99:156-62. PMID: 23040524 DOI: http://dx.doi.org/10.1016/j.fertnstert.2012.09.003

Roque M. Freeze-all policy: is it time for that? J Assist Reprod Genet. 2015a;32:171-6. PMID: 25428436 DOI: http://dx.doi.org/10.1007/s10815-014-0391-0

Roque M, Valle M, Guimarães F, Sampaio M, Geber S. Cost-Effectiveness of the Freeze-All Policy. JBRA Assisted Reprod. 2015b;19:125-30. DOI: http://dx.doi.org/10.5935/1518-0557.20150028

Roque $M$, Valle M, Guimarães F, Sampaio M, Geber S. Freeze-all policy: fresh vs. frozen-thawed embryo transfer. Fertil Steril. 2015c;103:1190-3. PMID: 25747130 DOI: http://dx.doi.org/10.1016/j.fertnstert.2015.01.045

Schwarze JE, Crosby JA, Zegers-Hochschild F. Effect of embryo freezing on perinatal outcome after assisted reproduction techniques: lessons from the Latin American Registry of Assisted Reproduction. Reprod Biomed Online. 2015;31:39-43. PMID: 25982094 DOI: http://dx.doi.org/10.1016/j.rbmo.2015.03.006

Shapiro BS, Daneshmand ST, Garner FC, Aguirre M, Hudson C, Thomas S. Evidence of impaired endometrial receptivity after ovarian stimulation for in vitro fertilization: a prospective randomized trial comparing fresh and frozen-thawed embryo transfer in normal responders. Fertil Steril. 2011a;96:344-8. PMID: 21737072 DOI: http://dx.doi.org/10.1016/j.fertnstert.2011.05.050

Shapiro BS, Daneshmand ST, Garner FC, Aguirre M, Hudson C, Thomas S. Evidence of impaired endometrial receptivity after ovarian stimulation for in vitro fertilization: a prospective randomized trial comparing fresh and frozen-thawed embryo transfer in high responders. Fertil Steril. 2011b;96:516-8. PMID: 21737071 DOI: http://dx.doi.org/10.1016/j.fertnstert.2011.02.059 
Siristatidis C, Sergentanis TN, Kanavidis P, Trivella M, Sotiraki M, Mavromatis I, Psaltopoulou T. Skalkidou A, Petridou ET. Controlled ovarian hyperstimulation for IVF: impact on ovarian, endometrial and cervical cancer - a systematic review and meta-analysis. Hum Reprod Update. 2013;19:105-23. PMID: 23255514 DOI: http://dx.doi.org/10.1093/humupd/dms051

Ubaldi F, Bourgain C, Tournaye H, Smitz J, Van Steirteghem A, Devroey P. Endometrial evaluation by aspiration biopsy on the day of oocyte retrieval in the embryo transfer cycles in patients with serum progesterone rise during the follicular phase. Fertil Steril. 1997;67:521-6. PMID: 9091341 DOI: http://dx.doi.org/10.1016/S0015-0282(97)80080-5
Van Vaerenbergh I, Van Lommel L, Ghislain V, In'tVeld P, Schuit $\mathrm{F}$, Fatemi HM, Devroey $\mathrm{P}$, Bourgain C. In GnRH antagonist/ rec-FSH stimulated cycles, advanced endometrial maturation on the day of oocyte retrieval correlates with altered gene expression. Hum Reprod. 2009;24:1085-91. PMID: 19176542 DOI: http://dx.doi.org/10.1093/humrep/den501

Wennerholm UB, Henningsen AK, Romundstad LB, Bergh C, Pinborg A, Skjaerven R, Forman J, Gissler $M$, Nygren KG, Tiitinen A. Perinatal outcomes of children born after frozenthawed embryo transfer: a Nordic cohort study from the CoNARTaS group. Hum Reprod. 2013;28:2545-53. PMID: 23832793 DOI: http://dx.doi.org/10.1093/humrep/det272 